\title{
El Greco. Algunos elementos de los fondos de las obras de época toledana
}

\author{
Francisco Javier Caballero Bernabé *
}

\begin{abstract}
RESUMEN ABSTRACT
El artículo se centra en diversos elementos que aparecen en los fondos de las obras de El Greco en su etapa

española y que se repiten con variantes, independientemente de los temás representados. Estos elementos permiten: Establecer comparaciones

con las obras de la etapa italiana. Conocer la evolución que algunos de ellos, como el paisaje o las vistas urbanas, sufren a lo largo de la obra del Cretense, o su faceta de cronista de su época y entorno.

The article is based on several items that can be seen in the background of the works painted by El Greco in his Spanish period, which are repeated with some variants independently from the themes represented. These items make possible certain comparisons with the Italian period. In addition, they will lead us to know the evolution that some of them, such as the scenery and the city views, suffer during the Cretan's work, or his facet of chronicler in his age and setting.
\end{abstract}

Al examinar el conjunto de la obra realizada por El Greco en su época española (¿1577?-1614) encontramos varias características que permanecen como constantes.

La repetición de elementos tanto en cuadros del mismo tema como en obras de temática distinta.

La evolución en la concepción de las obras y la disposición espacial de los elementos con el fin de no repetirse.

- Doctor en Historia del Arte. Universidad Complutense. 
La influencia de la época italiana, en particular de la etapa veneciana.

La "españolización» de los temas, que implica un abandono de lo italiano para evolucionar hacia un estilo más personal, más realista, con un claro reflejo de la sociedad, el urbanismo y el entorno en el que vive.

Crea temas nuevos "Vista de Toledo" que parecen el capítulo final de un largo proceso donde éste motivo lo hallamos de forma parcial.

La repetición de temas permite estudiar la evolución que han sufrido los fondos y los elementos, además de los protagonistas, la composición, el color, la luz, pincelada ${ }^{1}, \ldots$

La repetición de temas puede deberse a aspectos diferentes: El artista considera que ha encontrado la imagen ideal, fondos, elementos, ..., incluidos, por lo que no siente la necesidad de una creatividad continua. El artista guarda bocetos de las obras realizadas y cuando el cliente va al taller, El Greco, le muestra éstas obras y recibe las indicaciones de lo que desea o se lo especifica en el contrato. Satisfacer al cliente puede llegar a coartar la capacidad creativa en una época en la cual no es habitual encontrar establecimientos dedicados a vender obras de arte ni artistas que produzcan sistemáticamente al margen de los encargos.

\section{ARQUITECTURAS}

Al analizar el tema de la «Expulsión de los mercaderes del Templo» en las versiones de la col. Frick de Nueva York y de Londres (Fig. 1), se observa que las obras de El Greco muestran una continuidad con las versiones de Washington y de Minneapolis del mismo tema de época italiana? pero al mismo tiempo se aprecia que se trata de telas más evolucionadas y logradas. Lo que demuestra que EI Greco recordaba perfectamente las obras de su primera época y cuando se enfrenta a los problemas técnicos veinte años después comprende que la solución dada al tema dista de ser la más adecuada.

En las versiones españolas la concepción del espacio interior ha variado, pues la simetría de las columnas se ha roto para dar cabida a relieves de diferente tamaño a los lados del arco. También han cambiado las proporciones de los arcos. En general, los elementos arquitectónicos

Caballero Bernabé. F.J., La pintura de El Greco y la literatura ascético-mística española del siglo Xvi. Madrid, Univ. Complutense, 1990.

Pavon Maldonado, B., "El Greco arquitecto». A.E.A. XXXV, 139, 1962, págs. 209-220. 


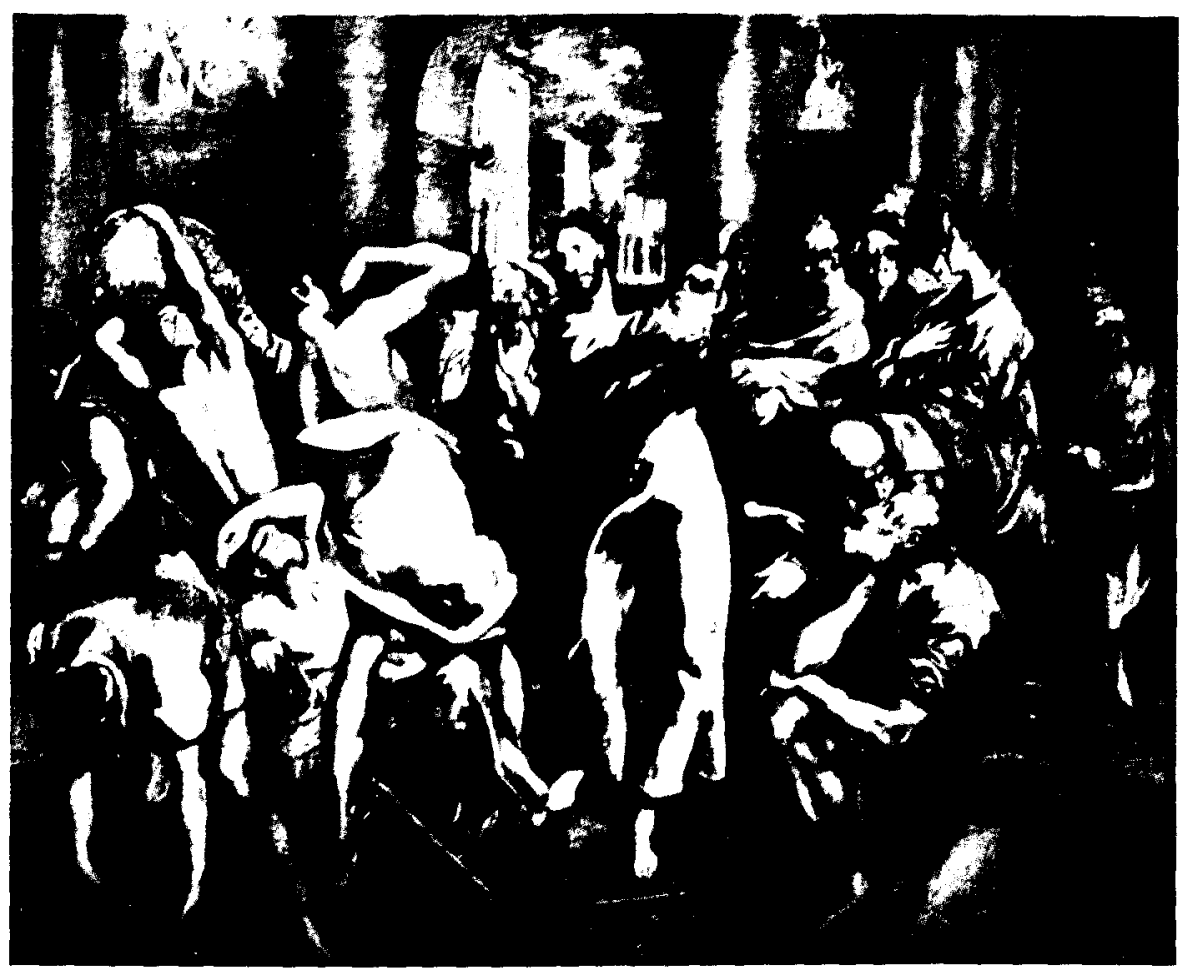

Fig. 1. Expulsion de los mercaderes del Templo. Londres.

se han simplificado en la estancia principal y se han complicado en la del fondo. La importancia del lateral y la amplitud del mismo ha disminuido considerablemente, eliminándose los elementos secundarios y las figuras masculinas del fondo que articulaban el espacio.

La versión de la iglesia de S. Ginés de Madrid de este tema, realizada por El Greco en los últimos años, ha eliminado los recuerdos venecianos como el gran arco, el paisaje urbanístico y la concepción del espacio interior de la sala principal. La escena aquí se desenvuelve en un espacio único y la arquitectura se convierte en telón de fondo, como si fuese un gran aparato escénico, de carácter teatral, ante el que se desarrolla una serie de escenas con una serie de personajes, protagonistas unos, comparsas otros. La compleja arquitectura que enmarca el altar sirve para indicar el centro de la acción principal. El fondo arquitectónico reproduce con fidelidad lo esenciai del altar mayor que centra el conjunto de lllescas y que recuerda a la arquitectura del retablo de $S$. Bernardino. Soehner se- 
ñaló que el relicario que ocupa el centro del nicho, entre columnas jónicas, recuerda el osario de Martín Ramírez, fundador de la Capilla de S. José de Toledo ${ }^{3}$. El relicario, de estructura compleja, mezcla las líneas rectas con las curvas rompiendo la uniformidad y rematándose en una estructura a manera de aguja terminada en una esfera. Todo lo cual recuerda a los relicarios toledanos de plata.

En la medida que las versiones españolas se alejan de los modelos italianos, El Greco abandona el objetivo que los tratadistas italianos tenían de reconstruir o recrear el Templo construido por Salomón en Jerusalén.

Un ejemplo que enlaza con las primeras versiones de la «Expulsión de los mercaderes del Templo" sería la "Cena en casa de Simón o Lázaro", donde contrasta la sencillez del espacio donde se desarrolla la escena, con la riqueza arquitectónica de los edificios tanto del fondo como del lateral derecho. No queda claro si la estancia se trata de un interior o de un patio.

En la etapa española los elementos arquitectónicos aparecen en muchas ocasiones aislados y son utilizados como simples elementos referenciales para situar a los personajes en la escena. Así, encontramos altos plintos sobre los que se levantan columnas de liso fuste toscano, "Julián Romero de las Azañas y su santo patrón» o con pilastras, "Aparición de la Virgen con el Niño a S. Jacinto", puertas "La Visitación". También edificios aislados en un paisaje más amplio, "La Inmaculada Concepción» o como simple atributo portado en la mano, "S. Agustin». Una obra en la que se combinan estos dos casos sería "Alegoría de la Orden de los Camaldulenses" a través de la iglesia que aparece en mitad del eremitorio y la minúscula representación que sostiene s. Romualdo en la mano. En todos los casos la referencia arquitectónica son los modelos italianos.

Las vistas de Toledo, en particular la "Vista y plano de Toledo" y el fondo del "Laocoonte" enlazan con las obras que tienen fondos arquitectónicos como los señalados, donde la arquitectura muestra un claro protagonismo (ver apartado titulado, Toledo). Éstas últimas telas, al igual que las versiones de la "Expulsión de los mercaderes del Templo" tienen en común, con obras italianas del mismo tema o la "Curación del ciego", su carácter de visiones urbanísticas.

En el conjunto de estas obras son observables dos versiones del urbanismo. Por un lado, la ciudad renacentista, "antigua", teórica (tratados de arquitectura de los siglos $x \vee$ y $\times v i)$ y real (Florencia, Mantua, ...). Por otro,

Gudiol, J., Doménikos Theotocopoulos. El Greco $(1541-1614)$. Barcelona. Ed. Polígrafa, 1971. págs. 277-278 
la ciudad medieval, "moderna», en la que lo conservado es fruto de aglutinar culturas dispares a lo largo de siglos y cuyo prototipo es Toledo.

El Greco recoge en los fondos arquitectónicos, el urbanismo existente en las diversas ciudades en las que vivió, el que se proyectaba en los tratados de autores clásicos y contemporáneos, y el que se estaba llevando a cabo en esos años.

Se convierte así en un cronista de la época presente y pretérita y en un estudioso de la arquitectura, al conocer los tratados de esos siglos. Habría que añadir que también en un erudito, que también intenta recrear los textos como en la pequeña "Anunciación" del Museo del Prado, obra de cronolcgía incierta, que se podría situar al final del período italiano o a principios del español.

Este interés por la arquitectura no es extraño, en el Cretense, si tenemos en cuenta los numerosos libros que sobre el tema figuran en los dos Inventarios que se realizaron tras su muerte y partiendo del hecho no seguro de que la mayoría de los que aparecen en el Inventario II, ya formaban parte de su biblioteca.

Autores como Serlio y Paladio, que figuran en los Inventarios están entre las fuentes de inspiración comúnmente aceptadas por los especialistas en El Greco. A estos habría que añadir otros como Vitrubio, Vignola, Sirigatti y Rusconi, ...

Esta relación entre El Greco y la arquitectura se hace más profunda si tenemos en cuenta, que al menos el ejemplar de Vitrubio comentado por Daniele Barbaro aparece con notas marginales, que Marias y Bustamante han comentado ampliamente ${ }^{4}$, al que hay que añadir "cinco libros de arquitectura manuscritos: uno con apuntes" (Inventario II).

Todo ello da pie a pensar que El Greco llevaba, en cuanto a la arquitectura teórica, una labor paralela a la pintura, que no encuentra en ésta última más que un pálido reflejo, muy lejos de la importancia que el artista la otorgaba.

\section{LOS INTERIORES DE LAS CASAS}

Los cuadros de El Greco que representan interiores son escasos y hay que tener en cuenta algunas de las obras señaladas en el epígrafe anterior.

4 Las ideas artisticas de El Greco. Comentarios a un texto inédito. Madrid, 1981. 
El grupo que analizaremos en este apartado contrasta vivamente con el precedente por la sobriedad, aunque también aquí encontramos modelos diferentes.

El tema de la «Adoración de los pastores» en sus diferentes versiones nos muestra un espacio pobre inspirado en la tradición neotestamental, pero interpretado libremente. Así el ejemplar de la colección Botín es el que más se acerca al modelo de pesebre, aunque no queda claro si se trata de una estancia amplia en la que apenas unas vigas, un tejado a modo de voladizo y un muro al fondo conforman el espacio o si se trata de una escena desarrollada en el exterior, junto a éstos elementos, aunque lo último tiene más sentido.

Las demás versiones muestran esa ambigüedad, pero al mismo tiempo se observa en el fondo un conjunto de muros a modo de pilares de los que arrancan arcos, elementos arquitrabados, ... en un estado ruinoso o semirruinoso que da a entender épocas precedentes de mayor enjundia y que por las proporciones no recuerda en nada a un pobre pesebre. Es posible ver aquí un simbolismo en el que se equipararian la arquitectura y el pueblo judio, que no atravesaba por su mejor momento histórico. Así el Niño-Dios nace en un mundo acabado y renueva a su pueblo y a la Humanidad.

La sobriedad y sencillez que muestran los interiores, reducen los elementos a simples espacios desnudos de paredes lisas, que se articulan, en algunos casos, para dar paso a otra estancia. Son simples muros a modo de telón de fondo, en los que situar uno o dos personajes, «S. Pablo" (Fig. 2), "S. Pedro y S. Pablo", "Sto. Domingo en oración en su celda". En todos ellos la simplicidad del escenario hace que la atención del espectador recaiga exclusivamente sobre los personajes. A veces, encontramos algún elemento (escalera con balaustrada, mesa, reclinatorio, suelo, ...) como referencia para crear perspectiva o para impedir que parezca un espacio ilusorio, plano, monocromo, similar al de los retratos o al de los apostolados. Los interiores muestran la realidad de la casa castellana perteneciente a gente sencilla de la época y la austeridad de la celda de un monasterio o convento. En ambos casos El Greco recoge el entorno en el que vive y con ello se convierte en cronista de su época, pues los interiores que contemplamos son los que corresponden a los edificios de las vistas urbanas de Toledo.

Los interiores de obras como "S. Ildefonso escribiendo" (Fig. 3) y «Retrato del Cardenal Niño de Guevara" son más ricos (mesa con tapete, sillones, objetos, dosel, brocado, ...) corresponden a representantes de la Iglesia, es decir a miembros destacados de la sociedad. También son más 


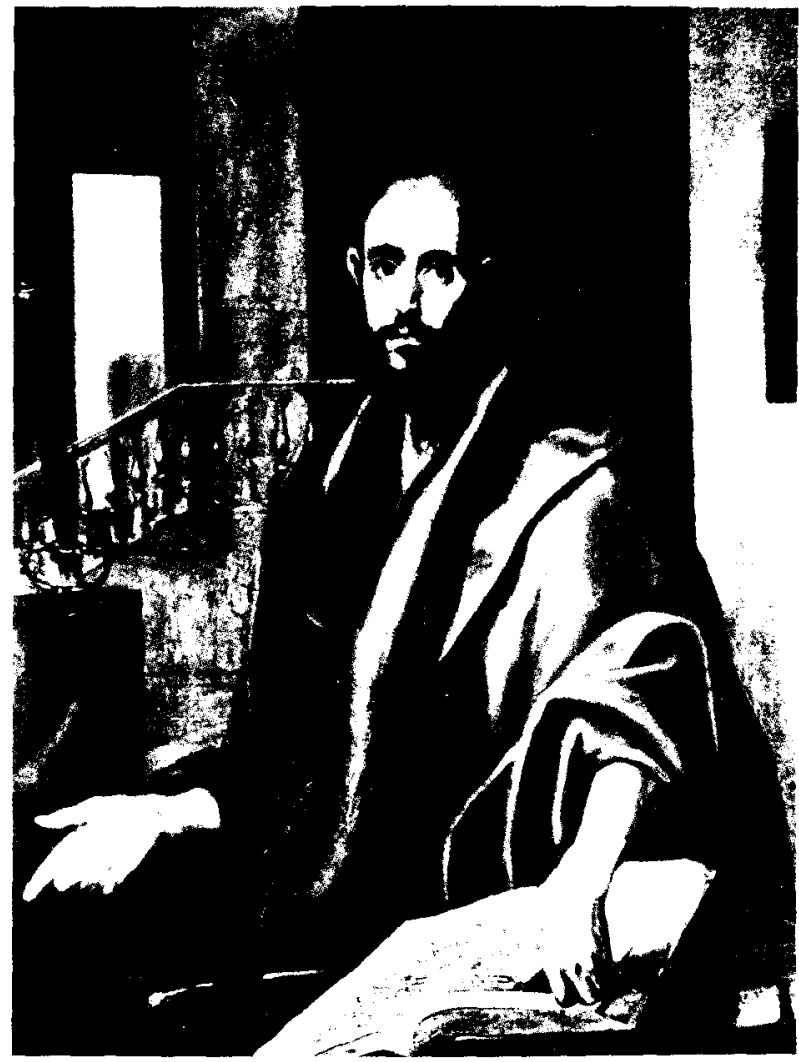

Fig. 2. San Pablo. Colecc. Marquesa de Narros.

complejos por tratarse de cuadros de gran tamaño. Estas características y el ser reflejo, ambos, de ambientes contemporáneos al artista, unen a dos obras cuyos personajes representados y la motivación del encargo son tan dispares. Por un lado, encontramos un santo de época pretérita del cual se capta su faceta de escritor y hombre piadoso, que parece ajeno a la realidad. Por otro, el retrato de un hombre contemporáneo, de fuerte personalidad, que mira al espectador directamente, que asienta sus pies en el suelo y que es consciente de su poder e importancia politica, religiosa y social.

El suelo de mármoles de coiores y formas geométricas alternadas, contribuye a dar profundidad al escenario, es curioso observar como en las obras de la última etapa de El Greco, vuelve a aparecer el suelo como recurso escénico de importancia, lo que hace suponer que retoma aspectos de su etapa italiana, aunque la concepción del mismo ha cambiado 


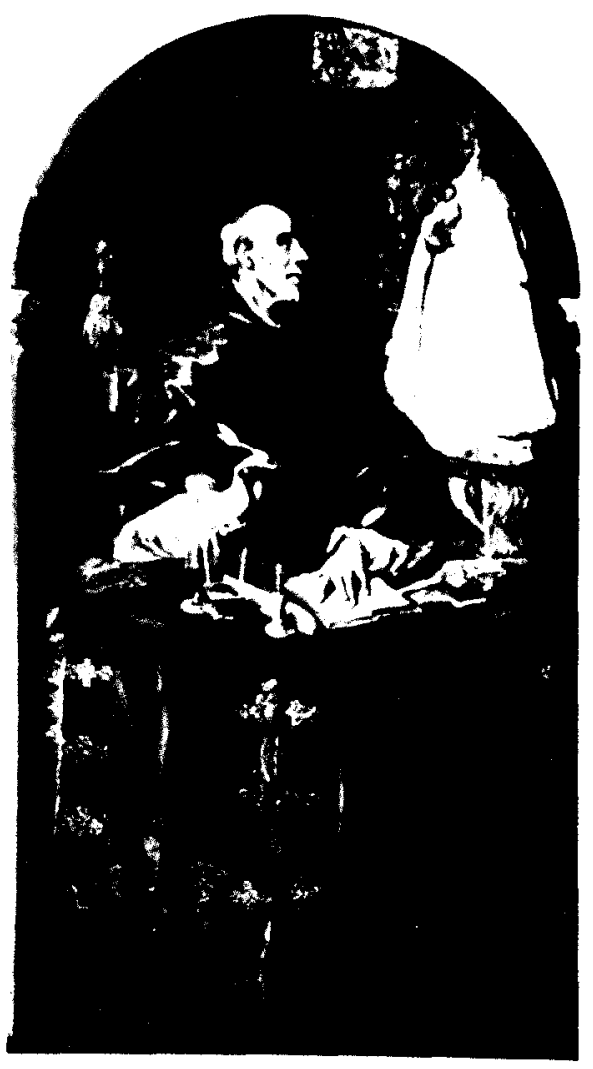

Fig. 3. San Ildefonso escribiendo. Hospital de Illescas (Toledo).

radicalmente. Esto se hace evidente al contemplar los "Desposorios de La Virgen" y la "Anunciación» del Hospital Tavera (Fig. 4). Aquí el suelo no está articulado o apenas, y es el elemento referencial único, es decir no forma parte de un complejo escenario arquitectónico, en el que se integra, perdiendo importancia frente a los monumentos.

En éstas obras, la perspectiva se articula casi exclusivamente a través de él por medio de las formas geométricas y la alternancia de colores. Lo que conduce al espectador hacia los personajes sin distraerle.

Los suelos son el elemento indicativo del nivel social del representado, "Retrato del cardenal Niño de Guevara", rico; "Anunciación", pobre, o de la categoria del edificio en el que tiene lugar la escena, "Desposorios de La Virgen», Templo. 

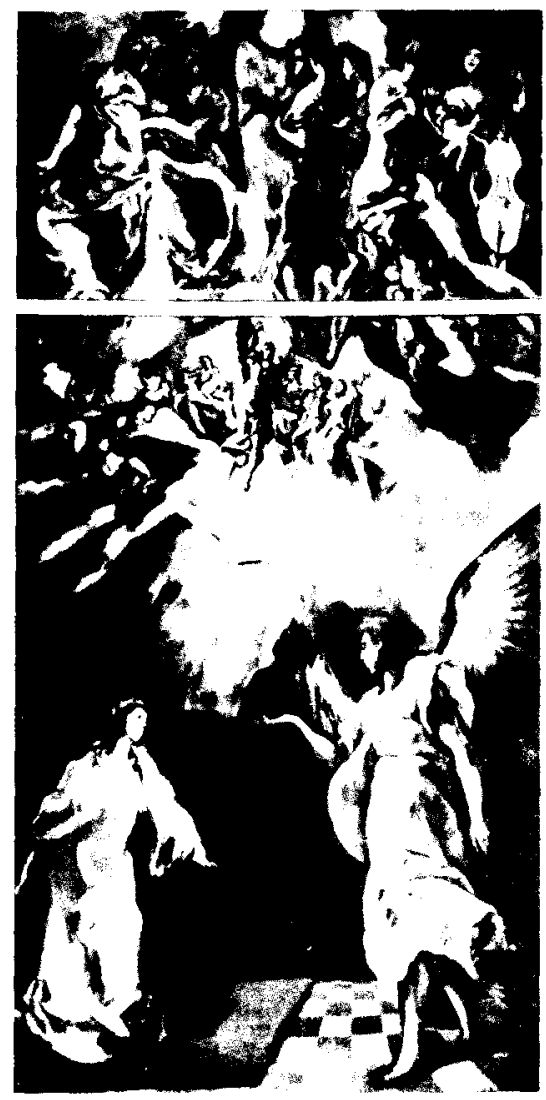

Fig. 4. Anunciación. Hospital Tavera. Toledo.

\section{EL PAISAJE Y SUS ELEMENTOS}

En la primera etapa de su estancia en España, el paisaje ocupa gran parte de los fondos de los cuadros de El Greco, como en el "S. Sebastián" de la catedral de Palencia (Fig. 5), donde se observa que la figura forma parte de un conjunto más amplio en el cual se integra, sin perder su preponderancia. Algo similar ocurre en el "Martirio de S. Mauricio y la legión Tebana».

El paisaje de la primera obra es de inspiración veneciana (Tiziano, Tintoretto, Veronés) ${ }^{5}$ y de las mismas caracteristicas que el "Retrato de Giu-

Wethey. H.E.. El Greco y su escuela. T. I. Madrid, 1967. pág. 55. 


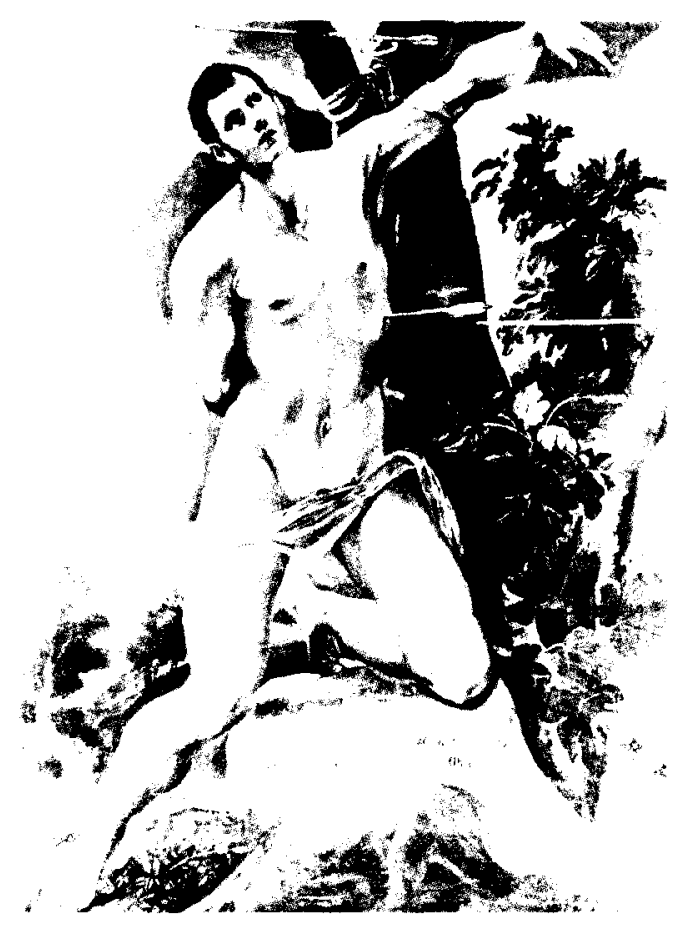

Fig. 5. San Sebastián. Catedral de Palencia

lio Clovio" de época italiana. Los árboles oblicuos, la vegetación, las flores, son realistas, pudiéndose identificar como higuera el árbol en el cual se encuentra atado S. Sebastián.

El Greco ha dado un gran protagonismo a la roca y el árbol, que adquiere una disposición paralela al Santo, discurriendo el tronco junto al cuerpo y una rama se abre hacia la derecha al igual que el brazo izquierdo de S. Sebastián.

En el "Martirio de S. Mauricio y la legión Tebana» (Fig. 6), el Cretense, coloca una franja de terreno entre los personajes apoyados en rocas y el espectador. Franja en la que coloca un tronco de árbol y diversas flores silvestres, una piedra y saliendo de ésta una víbora sujetando una cartela con la firma del pintor. Muchas son las interpretaciones que se han dado a éstos elementos, queriéndose ver en el tronco cortado del árbol, una vida cercenada en los años de juventud o una carrera pictórica frustrada en edad temprana, y en la víbora que muerde la cartela, el fracaso de El Greco y el quedar relegada su obra a un segundo piano frente a la de otro artista. 


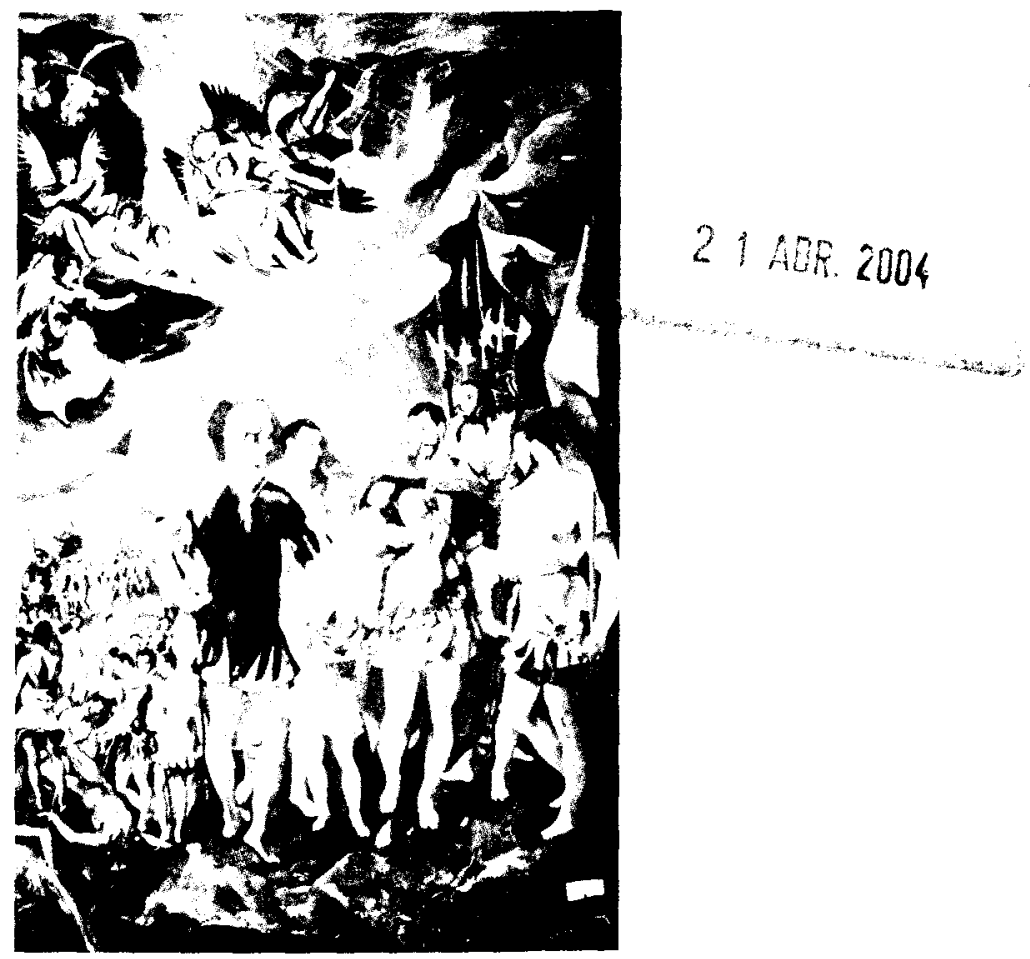

Fig. 6. Martirio de S. Mauricio y la legión Tebana. Monasterio de El Escorial (Madrid).

A través del escenario que semeja la falda de una loma, El Greco va articulando la distribución de las escenas, para terminar en un paisaje de serpenteante camino que conduce a un lugar elevado donde unas edificaciones configuran un conjunto urbano.

En el tema de "Sta. María Magdalena penitente" varias versiones, Worcester, Budapest y antigua col. Valdés, muestran un espacio en profundidad, con montañas, que enlaza con los mudelos italianos; mientras que las versiones de Kansas City (Fig. 7) y Sitges, han reducido el escenario y muestran aquellos elementos que son comunes a todas: una roca de gran tamaño y la hiedra.

La roca, que también aparece en temas como las «Lágrimas de $\mathrm{S}$. Pedro", "S. Francisco de Asís en meditación de rodillas" y en la versión en la que aparece de pie, "S. Jerónimo penitente", la "Oración en el Huerto", ..., realza, acerca al protagonista hacia el espectador, adopta formas antropomorfas, que continúan la silueta de la figura humana, mode- 


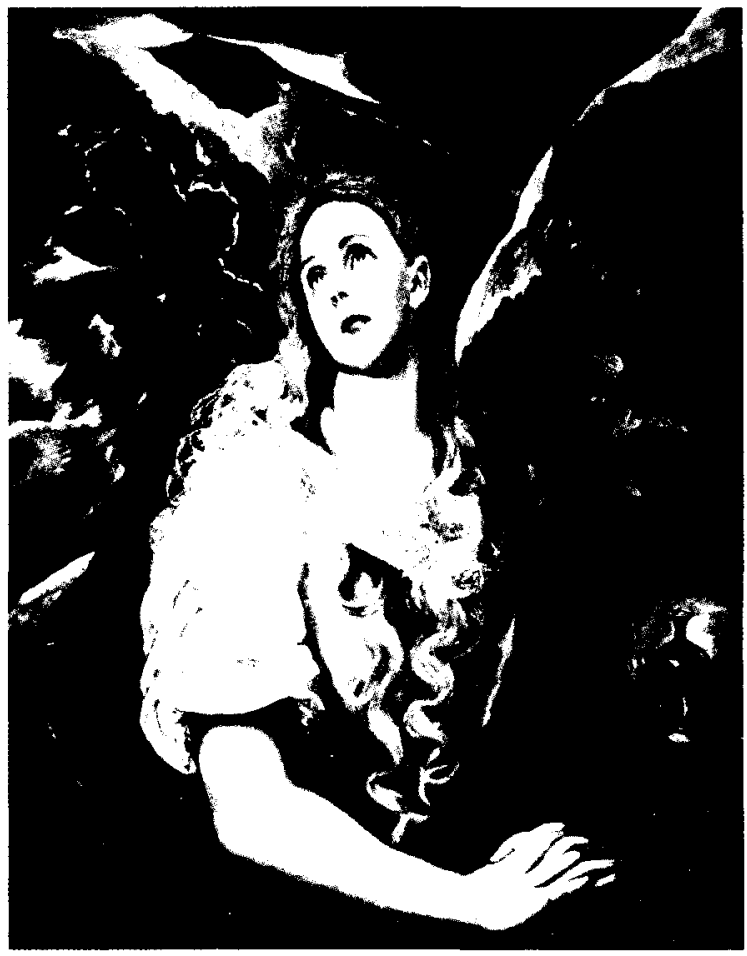

Fig. 7. Santa M. ${ }^{a}$ Magdalena penitente. Kansas City.

lándola y envolviéndola e incluso se constituye en prolongación de la misma. Al mismo tiempo se configura un escenario apropiado para la soledad, la penitencia, para la preparación al arrepentimiento, como se recoge en numerosos pasajes del Antiguo y Nuevo Testamento.

En el caso de la "Oración en el Huerto" (Fig. 8) la aparición de rocas y ramas de olivo sugiere una referencia directa al texto evangélico de $\mathrm{S}$. Lucas que denomina al lugar «monte de los olivos».

La hiedra, su emblema es Hidra, se interpreta como "Amistad constante y amor que no conoce separación", en Grecia significaba la constancia o tenacidad. Esta planta aparece unida en varios de los temas señalados de la obra de El Greco a la ascética y la meditación. Su presencia refuerza la idea de soledad que envuelve a la figura y el carácter ascético de la misma; llegando Archimboldo ha recogerla en la figura del "Invierno". Diversos autores interpretan que esta estación es el período idóneo para la penitencia, antes del resurgir de la primavera en lo temporal y es- 


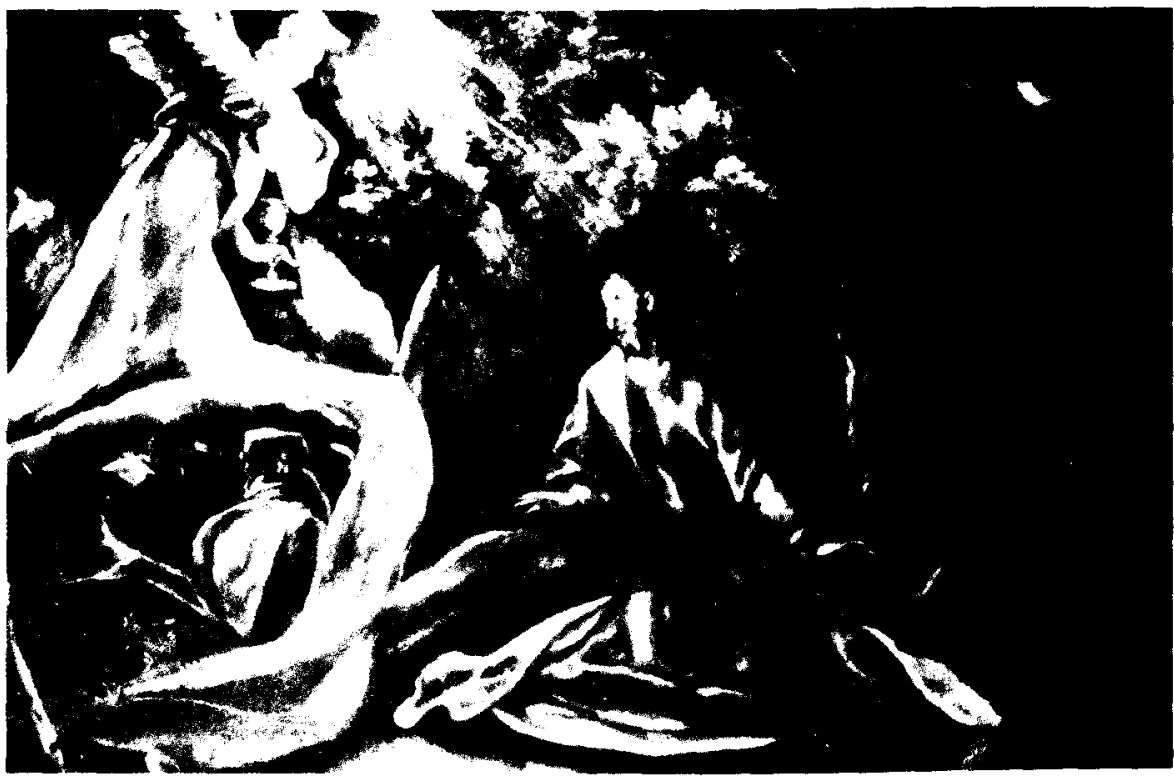

Fig. 8. Oración en el Huerto. Antigua colec. Valdés.

piritual. El verdor permanente de la hiedra indica que la vida sigue palpitando en el interior de las criaturas.

Otros elementos frecuentes en los fondos son la hierba, los árboles, las flores y las ramas quebradas. Todos ellos aparecen representados de forma realista, lo que puede contrastar con la concepción del paisaje que parece idealizado, pues se reconocen algunas de las especies arbóreas (olivo, higuera, ...) y se puede identificar la estación del año a través de la ausencia de hojas o por el color de las mismas (verdes, amarillas, ocres).

En las obras de El Greco no encontramos paisajes de invierno, con nieve, aunque unas leves pinceladas blancas en la cima de alguna montaña lo sugiere "S. Andrés y S. Francisco de Asís», pero sí de las restantes estaciones del año.

Existen varios temas en los que aparecen santos en solitario como "S. Pedro de pie con las llaves", el "Bautismo de Cristo", algunas versiones de la "Crucifixión», ..., en las cuales, los personajes se sitúan en un espacio abierto, del cual se recoge un franja de tierra de mayor o menos extensión, que va desde la sencillez de las rocas, que no nos permiten hacernos una idea concreta del lugar donde se encuentra el personaje; hasta la modulación del terreno a través de valles y montañas, elementos vege- 
tales o arquitectónicos, que se pierden en la lejanía. El resto del fondo, la mayor parte de la tela, se cubre con un cielo azul más o menos cubierto de nubes.

El punto de vista bajo en la mayoría de estos cuadros, contribuye a que la línea del horizonte sea baja y la franja de tierra estrecha; sin embargo, no desaparece, aunque no tenga una explicación lógica su presencia como en las parejas de santos, se evita con ello que las figuras puedan parecer celestiales, se ubiquen en espacios indefinidos o anacrónicos para uno, al menos, de los representados, pues son de diferentes épocas históricas como "S. Andrés y S. Francisco de Asís". Son recursos pictóricos utilizados por El Greco para situar a los protagonistas, pero al mismo tiempo nada nos impide pensar que estos paisajes prototípicos, variantes unos de otros y que el Candiota pudo imaginar, no se basan en los contemplados en los alrededores de Toledo.

Algo parece indiscutible, también aquí se ve una mutación con respecto a las obras primeras realizadas por El Greco tras su llegada a España, algo ha cambiado en la concepción del paisaje y en los elementos representados, pasando de lo imaginativo e ideal, que no desaparecerá del conjunto de su obra, a lo real y relacionado con el entorno del artista.

\section{TOLEDO}

Toledo, la ciudad que acoge al artista, aparece como una constante a to largo de su obra, fundamentalmente en los últimos años. Parece que el alma de la ciudad fuera penetrando en el espiritu de El Greco y se diese una fusión entre ambos elementos hasta ocupar gran parte de la superficie de la tela o convertirse en el tema del cuadro. Siguiendo los versos de Paravicino, podría afirmarse que ambos engendran parte de la inmortalidad que el otro posee.

La ciudad de Toledo en varias versiones de la "Crucifixión» (Fig. 9) está sustituyendo a Jerusalén, ciudad de la cual arranca la obra redentora. Toledo, como sede de la Iglesia Primada de España, es la ciudad que mejor enlaza con esa idea de la redención y de la jerarquía de la Iglesia a través de la comunión eclesial.

En el «Laocoonte» (Fig. 10), Toledo sustituye a Troya por su similitud a diversos niveles. Ambas se sitúan sobre un lugar elevado. Troya cerca del mar, Toledo abrazada por el río Tajo. Las dos tienen sólidas murallas y un glorioso pasado histórico y comercial. Además del simbolismo con marcado carácter político, que otros autores han establecido entre ambas, 


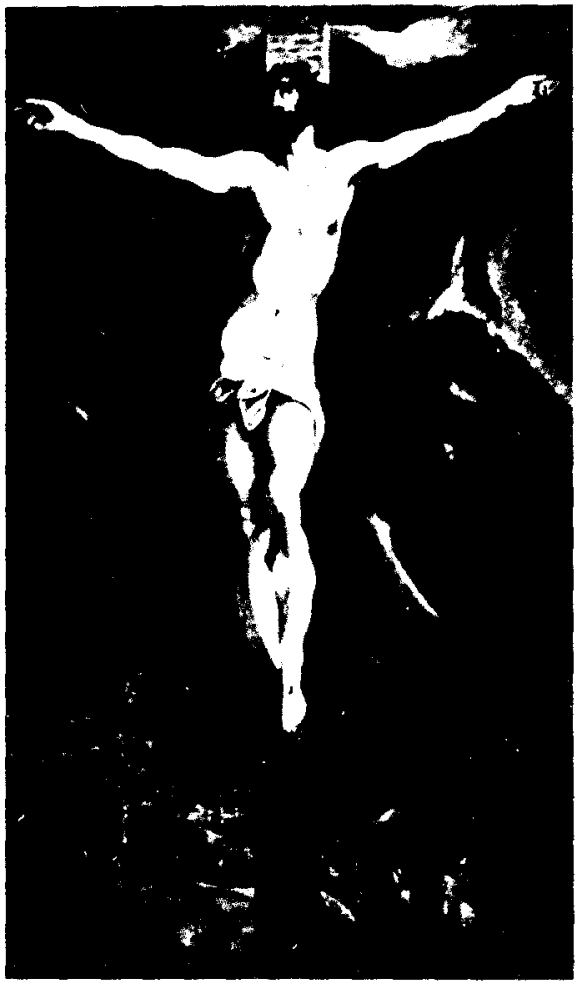

Fig. 9. Crucifixión. Colec. Zuloaga.

al ser las dos ciudades desplazadas históricamente, Troya por Micenas, Toledo por Madrid.

La misma libertad ha mostrado EI Greco al representar el caballo como un animal vivo que se dirige hacia la Ciudad. Es difícil conocer la razón de ésta libertad, pues la historia que narra la escena era muy conocida y esto podría haberle ocasionado al artista algún contratiempo a la hora de entregar el encargo. Cabe pensar en una reinterpretación de los textos que narran la escena en la Eneida de Virgilio (ecfrasis) ${ }^{6}$ a la manera de los cuadros del "Soplón» y del "Muchacho encendiendo una candela con

* Bialostocki, J.. "Puer Sufflans Ingnes». Arte in Europa. Scritti di storia dell'arte in onore di Edoardo Arslan. Milán, 1966, págs. 591-595

PLINIO el Viejo. Historia natural. XXXV, 138

Brown, J. El Greco de Toledo. Catálogo de la Exposición. Madrid, 1982. pág. 83 


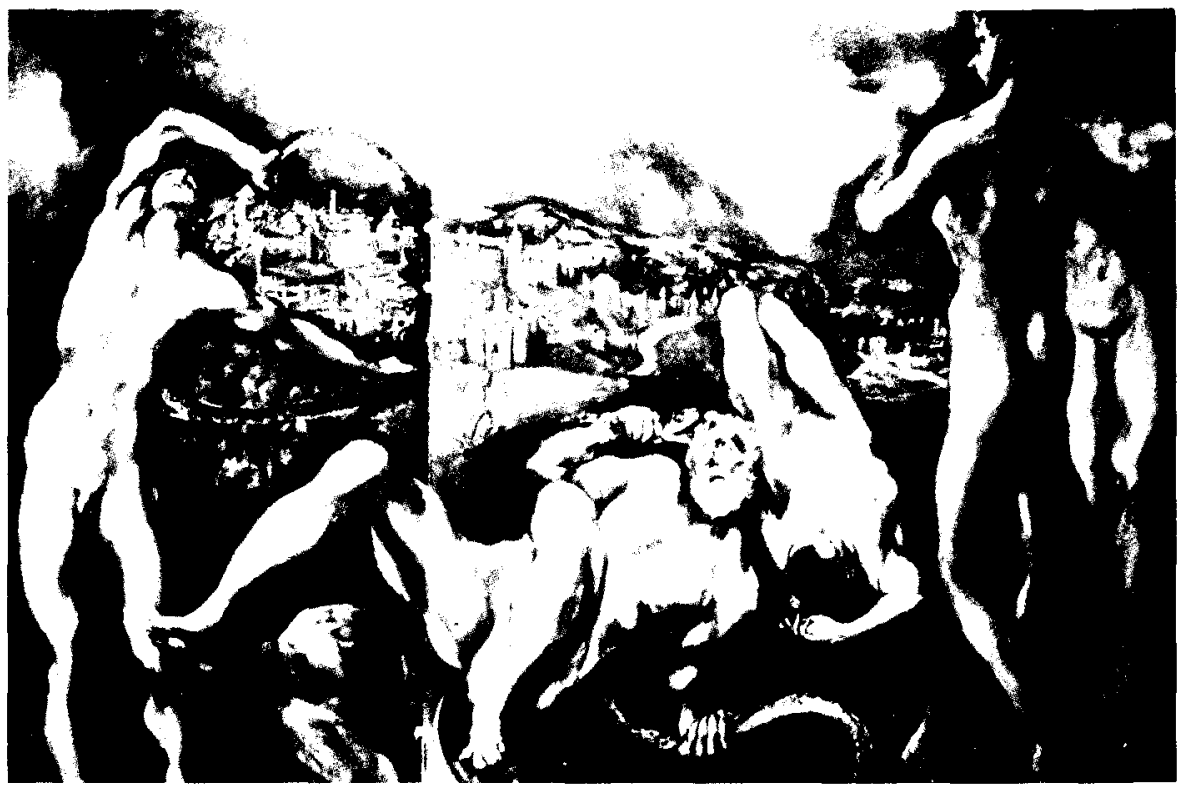

Fig. 10. Laocoonte. Washington.

mono y hombre", o la recreación de las composiciones urbanísticas citadas en el apartado arquitecturas.

De la misma manera que Toledo sustituye a otras ciudades, también encontramos que El Escorial aparece como alternativa a Toledo en algunas obras. Su presencia no encuentra una lógica interpretación. En su vertiente religiosa simboliza la fidelidad de España a la Iglesia católica y el triunfo de ésta sobre los enemigos de la $\mathrm{Fe}$. También se puede relacionar con las condiciones especificadas en el encargo.

Toledo aparece reconocible en las obras de El Greco, a través de algunos de sus elementos más característicos (catedral, alcázar, el río Tajo, ...), aunque no todos son tan fácilmente identificables. Sin embargo, El Greco no se limita a ser un mero reproductor de la realidad, pues como artista interpreta ésta, de manera que Toledo se convierte en una mezcla de realismo y subjetividad. Así, unos edificios se trastocan de lugar, adquieren o pierden importancia y protagonismo, y los cielos y el paisaje confieren al conjunto un aspecto dramático, fantasmagórico y romántico, en función de la luz y el color. Estas características son observables fundamentalmente en la «Vista de Toledo» (Fig. 11), “Vista y plano de Toledo» (Fig. 12) y en el "Laocoonte», aunque se anticipan en numerosas obras señaladas más arriba. 


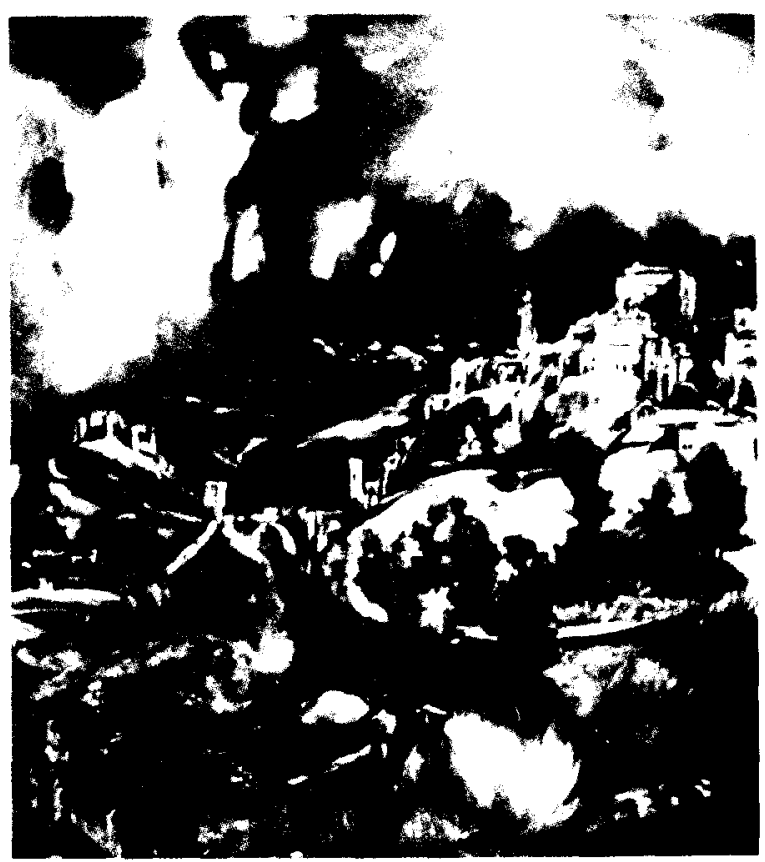

Fig. 11. Vista de Toledo. Nueva York.

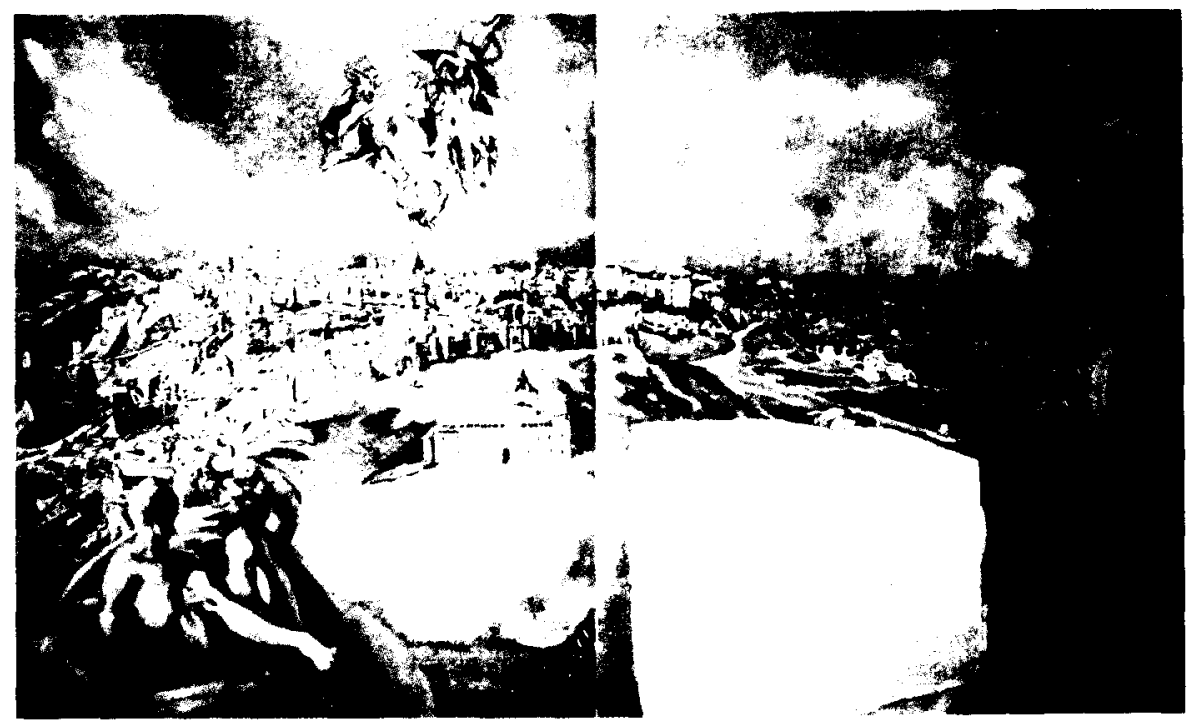

Fig. 12. Vista y plano de Toledo. Museo de El Greco. Toledo. 
La ciudad de Toledo reflejada por El Greco va más allá de lo arquitectónico, pues reduce el protagonismo de los edificios en beneficio del conjunto urbanístico y el entorno paisajístico, en una visión que hoy definiríamos como más moderna, pues arquitectura y paisaje se fusionan y complementan. El Greco enlaza así con el gusto surgido entre los coleccionistas e intelectuales del siglo XVI, pues las vistas de ciudades se pusieron de moda en esa época, fenómeno que se prolongaría a los siglos posteriores.

\section{LOS CIELOS}

Aparecen en buena parte de la obra de El Greco ocupando gran parte de la tela, debido al punto bajo de la composición, de manera que la figura humana se sitúa ante él produciéndose una sensación de gigantismo en la misma.

Los cielos que aparecen en las primeros temas, Sta. M. ${ }^{a}$ Magdalena, S. Francisco, crucifixiones, ..., muestran una clara influencia veneciana, que con el paso de los años se va transformando, ganando en variedad, riqueza, personalidad y dramatismo.

Son cielos con una gran carga trágica por medio de intensos colores azules, de escasa luz siempre en lucha por abrirse un hueco entre las numerosas nubes.

Los cielos reflejan todas las horas del día, especialmente las primeras y últimas, lo que acentúa el carácter dramático de los mismos.

La noche es también protagonista en algunos temas, "Oración en el Huerto", "Adoración de los pastores», donde la Luna es protagonista apareciendo en sus distintas fases de acuerdo con lo que marca el calendario católico para esos acontecimientos, es decir, El Greco se mantiene fiel a la tradición y preceptos de la Iglesia en este aspecto.

Existen dos clases de nubes en la obra de El Greco, aunque ambas tienen similares características. Se presentan como masas algodonosas, compactas, incluso sólidas, de buen tamaño.

Las nubes que aparecen en los cielos tienden a ocupar todo el espacio produciendo la sensación de "horror vacui" como señala Camón Aznar, repetidas veces, en su voluminosa obra titulada, Dominico Greco. Estas masas presentan una amplia gama de colores y de caprichosas formas.

En ocasiones semejan elementos activos que adquieren formas antropomorfas que contribuyen a enmarcar y realzar a los personajes, en particular las cabezas, sustituyendo a los nimbos de los santos y personas divinas. 
También encontramos nubes que invaden la escena principal sobre las que se apoyan e incluso se asientan, como si se tratase de objetos consistentes (estrados, rocas, ...), numerosas figuras de ángeles, objetos y edificios como se observa en los temas de la "Anunciación", "Vista y plano de Toledo", .... por ejemplo, e incluso sirven para transportar personas, "Oración en el Huerto".

Aristóteles en la Poética habla de la "máquina», término que puede interpretarse como objeto o medio extraño utilizado para introducir algo en el escenario que de otra manera, el espectador no podría contemplar. Interpretado el texto con libertad de criterio se podria afirmar que las nubes de El Greco cumplen esta misión? ? Idea que se refuerza si atendemos a la inscripción que aparece en "Vista y plano de Toledo", "HA SIDO FORZOSO PONER EL HOSPITAL DE DON JOAN TAVERA EN FORMA DE / MODELO PORQUE NO SÓLO VENIA A CUBRIR LA PUERTA DE VISAGRA MÁS / SUBÍA EL CIMBORRIOS O CÚPULA DE MANERA QUE SOBREPUJAN A LA CIUDAD Y / ...".

\section{LOS ACCESORIOS, LOS ANIMALES Y OTROS ELEMENTOS}

Son muchos y muy variados, la enumeración, obra por obra, resultaría demasiado prolija y la descripción tal vez innecesaria.

Algunos de estos objetos debieron ser de uso personal del artista o formaron parte del taller junto a los caballetes, telas, pinceles, ..., otros debió conocerlos en las casas y lugares públicos que frecuentaba.

Los libros, los encontramos desde las primeras obras italianas, siendo el más importante por contener la clave para identificar al personaje el "retrato de G. Clovio". En la etapa española aparece como atributo en el conjunto de los retablos de santo Domingo el Antiguo, concretamente en "S. Bernardo", y a partir de ese momento en muchos santos y apóstoles de características similares, es decir, generalmente en figuras aisladas y de carácter religioso; aunque también lo encontıamos en retratos de civiles, "Dr. Rodrigo de la Fuente", ... y de religiosos, "fray Hortensio Félix Paravicino", ...

Los libros pintados por El Greco tienen tamaños diversos, predominando los grandes, que tenían un contenido religioso. Los presenta, el artista,

Caballero Befnabe. F.J., "La "Poética" de Aristóteles y la pintura de El Greco". En Homenaje al Profesor Hernández Perera. Madrid. 1992, pags. 279-285. 
con las encuadernaciones propias de su época, lo que confiere a los personajes un sentido de coetaneidad con el pintor. Algunos nos muestran la riqueza que encierra su interior a través de uno de los folios, "S. Lucas" de la catedral de Toledo (Fig. 13); otros, los escritos, aunque, en general, no se plasman las letras, sino simples lineas, salvo en el caso de "s. Pablo" de la col. de la marquesa de Narros, donde el libro muestra caracteres griegos.

En muchas obras encontramos papeles con varias posibles finalidades. Unos, semejan cartas y refuerzan la identidad del representado, «S. Pablo" del Apostolado de la catedral de Toledo y del Museo de El Greco, como autor de escritos a colaboradores y comunidades cristianas. Otros, son cartelas en las cuales el Cretense estampa su firma en caracteres griegos, «El Expolio», "Asunción de la Virgen», ... Estos papeles aparecen

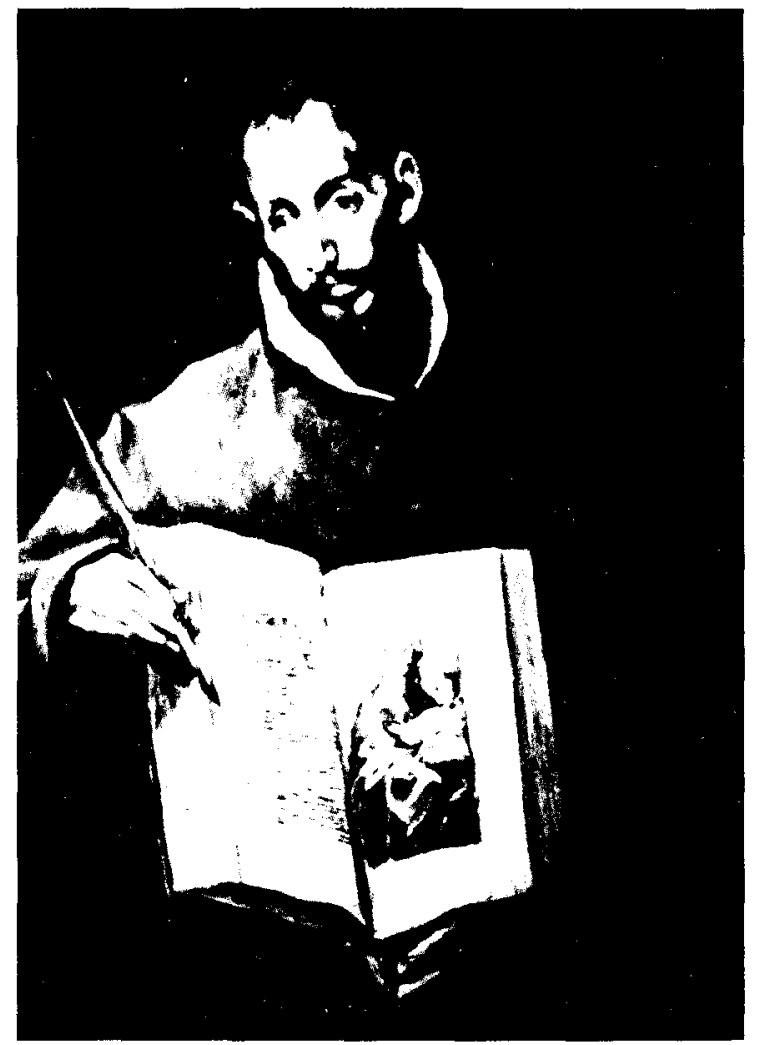

Fig. 13. San Lucas. Catedral de Toledo. 
en los lugares más variados, con la naturalidad de la carta sostenida entre las manos o el papel descuidadamente caido en el suelo, que inmediatamente atrae la atención del espectador. El ejemplo que más comentarios ha suscitado siempre ha sido la cartela que aparece en el "Martirio de S. Mauricio y la legión Tebana" por la simbología que ya hemos comentado más arriba.

Las plumas y los tinteros, suelen ir unidos a los libros en muchas obras, para recalcar la faceta de escritor del representado. La obra que mejor recoge los tres elementos es "S. Ildefonso escribiendo", donde aparecen sobre una mesa, junto a otros objetos de escritorio, adquiriendo, por la calidad de su ejecución, un protagonismo compartido con el Santo y constituyendo un fragmento equiparable a un bodegón.

Los crucitijos son frecuentes en temas de santos penitentes como Sta.

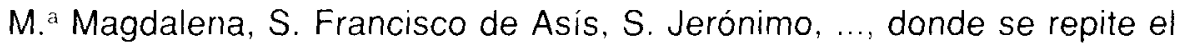
modelo de cruz, palo vertical largo y transversal corto, y de figura de Cristo, que guarda relación con las imágenes de las crucifixiones.

La calavera aparece también en temas de santos penitentes, como los señalados más arriba, en las crucifixiones, ... La posición varía, para evitar repeticiones sistemáticas y para mostrar su capacidad técnica, aunque es el mismo modelo.

Estos últimos elementos se utilizan como símbolo del carácter ascéticomístico de los representados y como motivos para la meditación y reflexión de todo buen católico, recordando el sacrificio de Cristo para redimir la Humanidad, y la brevedad de la vida y la renuncia a todo lo que tiene que ver con el mundo para buscar lo que permanece por toda la eternidad, Dios. Esta misma simbología es aplicable al reloj de arena, "S. Jerónimo penitente».

Como símbolos alusivos a los personajes o escenas en los que aparecen encontramos:

Cruces de distintos tipos, "S. Andrés", "S. Juan bautista", ...

Llaves en la figura de $S$. Pedro.

Báculos, "S. Agustín, «S. Ildefonso».

Paleta, solo un ejemplo, "retrato de Jorge Manuel".

Mitras, «S. Bernardino de Siena».

Bonetes, "retrato del cardenal Niño de Guevara", ...

Frasco de perfume, "Sta. M. ${ }^{\text {a }}$ Magdalena".

Jarrones, tema de la Anunciación. 
Azucenas, en el tema anterior y en "S. Antonio de Padua".

Dalmática, "Aparición de la Virgen con el Niño a S. Lorenzo".

Cordero, "S. Juan Bautista», la figura de Sta. Inés en la "Virgen y el Niño con Sta. Martina y Sta. Inés».

León, en la figura de sta. Martina del tema anterior.

Asno y buey, "Natividad", "Adoración de los pastores».

Dragón, "S. Juan Evangelista», “Adoración del Nombre de Jesús».

Serpiente, "Laocoonte», ...

Los elementos de carácter militar, los encontramos en numerosos cuadros.

Armaduras, soldado de «El Expolio», la del señor de Orgaz en el cuadro del Entierro, ..., guardan semejanza la mayoría de ellas y se corresponden con las existentes en la época del artista.

Lórigas, que interpretan con libertad las corazas romanas cuadro de $\mathrm{S}$. Mauricio, ... Se inspiran en modelos italianos comúnmente utilizados en el siglo XVI.

Espadas, utilizadas como símbolo en cuadros de tema religioso, haciendo alusión a la muerte del representado, «S. Pablo», ... o a su condición de militar "S. Martín y el mendigo", ..., y en personajes civiles, "Caballero de la mano al pecho". Todas ellas reflejan modelos de la época del cretense, constituyendo un caso singular y anacrónico la bella espada nazarí que porta uno de los compañeros de S. Mauricio.

Encontramos en los cuadros de El Greco muchos objetos de la vida cotidiana y que el artista pudo recoger de su entorno, de manera que sirven para reconstruir el ambiente de la segunda mitad del siglo XVI y principios del siglo XVII, citaré algunos ejemplos.

Cestos de mimbre, «Expulsión de los mercaderes del Templo".

Canastillas de labores, ropas y lienzos blancos, "Anunciación".

Hacha, "Bautismo de Cristo".

Fruteros y frutas, tema de la Sagrada Familia.

Tapices, "retrato del cardenal Niño de Guevara».

Cojines, "Adoración del Nombre de Jesús», ...

Debemos recordar que muchos de los accesorios, los animales y los objetos, tienen un contenido simbólico concreto, como se adivina por los casos comentados. 